\title{
Piloting a new role in mental health - prison based health trainers
}

\author{
Coral Sirdifield \\ Research Assistant, University of Lincoln
}

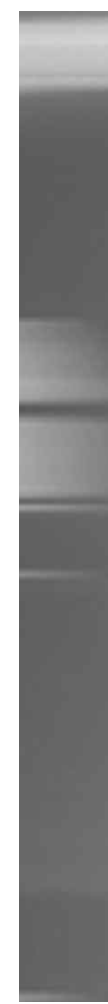

\begin{abstract}
Prisoners in the UK are in a poor state of health compared to the wider population, often experiencing numerous physical and/or mental health problems. Many prisoners have had little contact with health services, and research suggests that the standard of health care provided in prisons is not equivalent to that provided in the community. This article introduces Care Services Improvement Partnership Health Trainers - an initiative aiming to provide prisoners themselves with the skills to address health inequalities among their peers. Initially, it discusses the origins of these Health Trainers. It then examines prisoners' views on how training as a Health Trainer has influenced their attitudes and behaviour, and outlines possible implications of providing this kind of training to prisoners in terms of them using their knowledge to influence other prisoners' mental health.
\end{abstract}

\section{Keywords}

prison; mental health; Health Trainer; peer-education

\section{Background}

UK prisoners generally lead unhealthy lifestyles including misusing drugs, smoking and misusing alcohol (HMPS/ DoH, 2001). Consequently, prisoners are in a relatively poor state of health compared to the wider population, often experiencing multiple physical and/or mental health problems. Research shows that the incidence of mental health disorders is much higher in the prison population than the wider population with up to $90 \%$ of prisoners exhibiting signs of a mental health disorder (Singleton et al, 1998; Brooker et al, 2002). For example, Brugha et al (2005: 774) estimate the weighted prevalence of probable functional psychosis in the general UK population to be 4.5 per thousand, while in the prison population, they estimate it to be 52 per thousand - over 10 times higher. Similarly, Singleton et al (1998) estimate the incidence of neurotic disorders at between $40 \%$ and $76 \%$ in the prison population compared to just $17.3 \%$ of adults of working age in the wider population.

Prisoners are unlikely to have had much contact with health services while in the community (Department of Health, 2004: 129), and for some individuals, time spent in prison may be the only time that they engage with health services. However, the prison population is continuing to increase (HMPS, 2006) and research shows that despite prison reception screening, in many cases mental health disorders also go undetected while an individual is in prison (Birmingham et al 1996; SEU, 2002). Pressure on prison health care services is likely to increase as the population continues to rise.

In 1996 Her Majesty's Inspectorate of Prisons argued in Patient or Prisoner: a new strategy for healthcare in prisons that prisoners should receive an equivalent standard of health care in prisons to that provided in the community. However, in 2002, the Social Exclusion Unit stated that:

\section{'Despite isolated examples of good practice by the Prison Service, NHS and voluntary sector organisations, most prisoners with mental health problems are not currently receiving the care and treatment they might expect outside. Research suggests that prisoners are twice as likely to be refused treatment for mental health problems inside prison than outside' (SEU, 2002: 71).}

Thus, there is a greater need for mental health care services in prison than in the general population, but the service provision is not adequate to meet these needs. Many individuals are not receiving the care that they need which may increase their chances of re-offending and lead to increased costs for the NHS further down the line.

In order to improve this situation, there is an increasing need for prison staff to be able to recognise the signs and symptoms of mental illness. Some improvements have been made already - including the provision of prison inreach teams and NHS-led primary care teams to assess prisoners' mental health (Brooker et al, 2005). Additionally, a self-directed mental health awareness workbook has been 
rolled out to a number of prison staff as part of ACCT (Assessment, Care in Custody and Teamwork) training through the CSIP (Care Services Improvement Partnership), and Health and Social Care in Criminal Justice Programme (HSCCJP) (Brooker, 2006). Furthermore, in April 2006 responsibility for the provision of health care services in prisons moved from the Home Office to the NHS.

However, one could argue that relatively little resource has been allocated to educating prisoners to recognise the signs and symptoms of mental health disorders. This article provides an introduction to a new initiative that is beginning to do just that - CSIP Health Trainers. This initiative aims to provide prisoners with the skills to address health inequalities among their peers. Initially, this article provides an overview of the progress made during the first eight months of a pilot project in terms of adapting core Health Trainer competencies for use in prisons and designing a training course to teach these competencies to prisoners. Second, the sections of the course relating to mental health and well-being are described in more detail. Third, the results of a focus group conducted with Health Trainers at one prison are presented to show these prisoners' views on how the course is influencing their attitudes and behaviour, together with possible implications of providing this kind of training to prisoners in terms of Health Trainers' ability to influence other prisoners' mental health. Finally, recommendations are made regarding the focus of future research on this topic.

\section{What is a Health Trainer?}

The 2004 white paper Choosing Health: Making Healthy Choices Easier aimed to reduce health inequalities by supporting the public in making more healthy and informed choices regarding their health. The government particularly emphasised working in disadvantaged areas and with previously excluded and marginalised groups to enable them to make faster improvements in health, and thus reduce health inequalities. Rather than disseminating advice from on high, the government proposed that responsibility for improving health should lie with communities themselves. Consequently, they introduced the role of a Health Trainer into deprived communities.

Initially, Health Trainers were recruited from these deprived communities, using a draft set of core competencies and job descriptions that were trialled in 12 early adopter sites. These sites were areas of the UK, which the government identified as being the most disadvantaged. Health Trainers were employed to signpost individuals into relevant local health services. They were also trained to support individuals in making and following personal health action plans to achieve goals such as weight reduction or quitting smoking. The boundaries of the role were very fluid in terms of the types of population worked with and the areas of health (eg. healthy eating/smoking/sexual health) that were focused on. This has resulted in a wide variety of Health Trainer models being implemented across the country. A number of local-level evaluations of these early adopter sites are now underway, and there are proposals for a national evaluation of the Health Trainer role.

\section{CSIP Health Trainers}

After the core competencies and job descriptions had been trialled in the early adopter sites, a project led by CSIP adapted them for use in the prison environment. The project team aimed to train prisoners in a variety of types of establishment as Health Trainers. The project was advertised across England, resulting in five prisons and one probation area volunteering to take part in the pilot - namely HMP Drake Hall, HMP Stafford, HMP Wandsworth, HMP Kingston, HMPYOI Swinfen Hall and Portsmouth Probation area.

Representatives from the University of Portsmouth, Prison Health (Department of Health), CSIP, PCTs, and Prisons and Probation worked together over approximately six months to revise the community-based job descriptions and to develop a training package based around the Department of Health core competencies.

The general content of the community-based Health Trainer job description was deemed to be quite acceptable for use in prisons, but some of the wording was changed to reflect the fact that the Health Trainers would be operating in a prison environment, and to make it more user-friendly for the prisoners being trained.

The finished training package covers areas such as communication skills, identifying professional boundaries, promoting health and well-being, behaviour change, healthy eating, physical activity, smoking, and mental health and well-being. Its design accounts for prisoners' likely literacy levels and attention spans. Consequently, it is a mixture of formal teaching and hands-on exercises that can be taught in short sections over a number of weeks. The flexibility in the way in which the programme is delivered recognises the need to book group rooms and to 
have staff free to escort prisoners to and from the course. Additionally, accreditation is being sought from the National Open College Network (N/OCN) to make it comparable with other prison-based programmes. Prison staff felt strongly that this was an important factor in motivating prisoners to attend the course, and in making the programme relevant to resettlement objectives.

The approach taken to recruiting Health Trainers varied in each establishment, reflecting differences in terms of establishments' population size, layout, resources and security issues. Thus, in some prisons, the role was advertised through a flyer, and prisoners were invited to complete formal applications, while in others particular prisoners that staff considered to be trustworthy and motivated were selected for the role. In all cases, tutors agreed that Health Trainers would need good communication skills, an interest in health promotion, and to be motivated enough to complete the course. Additionally, it was deemed inappropriate to recruit sex offenders into the role. In prisons implementing an 'open' application process, they aimed to recruit one Health Trainer per wing/two houses to ensure that all prisoners have equal access to the service and in order for each Health Trainer to have a manageable number of potential clients. For example, in Drake Hall one Health Trainer was recruited per two houses meaning that each Health Trainer would have approximately 39 potential clients. This figure varies between establishments, and changes as the total population of the establishments fluctuates.

\section{Description of the training programme/course}

Several sections of the course may have implications for the mental health and well-being of both the Health Trainers and their peers. The content of these sections is briefly outlined below.

The section of the course relating to exercise outlines:

- anatomy and physiology

- definitions of 'fitness'

- how to plan, implement and evaluate a personal exercise programme

- a range of exercises that it is possible to do in a cell and/or the prison gym

- types of fitness training

- recommended levels and benefits of exercise

- exercise safety.
The section on healthy eating outlines:

- general dietary guidelines, nutrition and food groups

- how to reduce intake of fat, sugar and salt, and increase intake of fibre

- weight management.

The section relating to mental health and well-being covers the following topics:

- what stress is

- positive and negative aspects of stress

- how to recognise the signs and symptoms of stress

- physical, emotional and behavioural effects of stress on health

- causes of stress (including prison)

- stress management techniques

- how to make a stress management action plan.

Evidence from a focus group with Health Trainers at one prison suggested that the knowledge that they gained from these sections of the Health Trainer course had already started to change their attitudes and behaviour in these areas. These prisoners were already making changes to their own behaviour and beginning to influence other prisoners' behaviour, which may have implications for their mental health as outlined below.

\section{Methodology}

The research aimed to investigate the views of several Health Trainers at one establishment on the effect of their training on their attitudes and behaviour. Gaining access to interview prisoners is often problematic, and may divert staff from their everyday duties. However, a range of individuals' views can be captured at one time using focus groups. Furthermore, many prisoners have low levels of reading and writing skills (Home Office, 2001) making it difficult for them to complete surveys. Therefore, a focus group was employed as the method of data collection for this study as it allows the views of several individuals to be gathered in a relatively short space of time and does not discriminate against individuals with basic skills difficulties (Kitzinger, 1995).

Moreover, focus groups promote in-depth investigation of participants' perspectives on a topic, empowering participants to create their own priorities for discussion rather than being led completely by the researcher. Thus, for example, prisoners were asked what effect the course 
had on their level of knowledge about health topics, and were then asked whether it had changed their attitudes in any of the areas of health that they discussed, rather than areas pre-determined by the researcher. Additionally, focus groups encourage participants to question each other's opinions rather than answer the questions one at a time, allowing the researcher to gain a sense of not only what participants' opinions are, but examples of why they hold those opinions (Kitzinger,1995).

The focus group was part of a wider piece of work examining prisoners' views on the effectiveness of the Health Trainers' course. Therefore, a list of open questions was formulated regarding the following areas of investigation:

- what motivated the prisoners to train as Health Trainers

- prisoners' views on the course - what they liked best and least, and how they thought it could be improved

- the effect of attending the course on the prisoners' attitudes and behaviour.

The results of the latter area of investigation are reported in this paper.

The focus group was conducted with an opportunistic sample of prisoners attending the Health Trainer course at one prison and lasted for around an hour. Participants were informed of the purpose of the study and given assurances regarding confidentiality and anonymity. The focus group was tape recorded and transcribed verbatim with the prisoners' permission. Unfortunately, only two of the eight Health Trainers approached to be part of this study consented to be interviewed on the day. Therefore, due to the small sample size, data was then manually coded into key concepts/themes. Initially, the data was categorised according to the three areas of enquiry detailed above. It was then broken down into sub-themes/concepts such as 'pro-social modelling' or 'behaviour change' (Coffey \& Atkinson, 1996).

\section{Findings}

Analysis of the focus group data shows that the Health Trainers believe their training has influenced their own attitudes and behaviour in a number of ways. The prisoners believed that there was a need for pro-social modelling:
1: 'They've got to be erm good about themselves as doing the right thing with themselves.'

Int: 'Yeah.'

1: 'Even if they're not doing everything.'

Int: 'Yeah.'

1: 'They're putting things into practice.'

2: 'Mmm.'

1: 'And they do... they're starting that goal that erm.'

Int: 'Yeah.'

1: 'Because you've got... if you're gonna give advice and you're to tell people you've got to have good knowledge of it yourself.'

Int: 'Yeah.'

2: 'You have to be living the part.'

Consequently, some of the Health Trainers were making changes to their behaviour. For example, learning about nutrition on the course had led to one Health Trainer changing their diet:

1: 'So I looked at what (name) was eating and since I've started eating that, just little things like lentils... and I've never ever eaten that before.'

Int: 'Would you have thought of that before you did the course?'

1: 'No.'

Int: 'Would you not have looked at (name) and thought...'

1: 'No it wasn't until we did the nutrition about.'

Int: 'Right.'

1: 'I knew that you've got to eat your five fruit and veg.'

Int: 'Yeah.'

1: 'But I... I'm now counting how many I eat and also colourful vegetables (laughs) I've got that in my brain. I'm getting quite actually addicted to all this!' 
Additionally, one Health Trainer had given up smoking:

1: 'And doing things. I was a heavy smoker as well.'

Int: 'Oh right yeah.'

1: 'A very heavy smoker erm, I'm in the process of giving up now.'

Int: 'OK.'

1: 'So I'm on the patches I don't smoke during the day.'

Int: 'Right.'

Research from the Natural Justice Project based at the University of Oxford has linked disruptive and offending behaviour with poor nutrition. Therefore, if Health Trainers are able to improve prisoners' diets there may be the potential to reduce their offending behaviour and improve their mental health. This is an area that Health Trainers were already beginning to influence:

1: 'I mean I heard that the cake on Saturday had the icing on top wasn't real icing, it was made by margarine, which is just like lard.'

Int: (laughs)

1: (laughs) 'And then I'm saying to everybody "OK do you really need that cake? Can you get a piece of fruit?" "No we want the cake...we've been waiting all week for this cake." "OK so take the top off the cake!".'

Int: (laughs)

1: "Just slice it off" OK and they were all like slicing it off.'

CSIP Health Trainers will also be able to recognise the signs and symptoms of stress in other prisoners, and give them advice regarding stress management techniques. Arguably, prisoners are more likely to recognise these signs in their peers than staff are. Moreover, research suggests that prisoners may prefer to discuss problems with another prisoner rather than a member of staff, and would be more likely to take a prisoner's advice on board (Devilly et al, 2005). Comments from the Health Trainers reflected this view:
2: 'So to for us to then say "oh it's difficult, it's hard".'

Int: 'Mmm, mmm.'

2: 'They, the person opposite you is going "yeah it is difficult, hard" but then you can say ah but there's this and this and this that you can do.'

Int: 'Yeah.'

2: 'Then the response is far better from the person.'

Int: 'Do you think?'

2: 'Because they can say "ooh well if you're saying it's OK then maybe it is OK" erm if you're doing it, maybe I can do it too.'

Feedback from Health Trainers may also highlight factors inherent in the prison environment that have a negative effect on prisoners' mental health, but it may not always be possible to change these factors. Therefore, there is a need for this role to be carefully managed and for there to be clear boundaries on the role so that they refer individuals on to prison health care services as necessary, rather than trying to tackle problems that are beyond their level of skill/learning themselves (Devilly et al, 2005). There is also the possibility that prisoners trained as Health Trainers could abuse the system and use information that a prisoner has confided in confidence against them. This was reflected in the comments from the prisoners interviewed:

2: 'And so the most important thing of all is about respecting the confidentiality erm...'

Int: 'Yeah.'

2: 'If a Health Trainer can't do that then they can't be in that role, not at all.'

Moreover, there is the possibility that training prisoners as Health Trainers would result in power imbalances between them and other prisoners. Thus, in order for the Health Trainer role to be successful, care needs to be taken in how it is managed and implemented, as discussed below.

\section{Discussion}

Health Trainers are being employed in a variety of ways in communities and prisons across the country to signpost 
individuals in deprived communities into appropriate health services, and to produce personal health improvement action plans with them. While no one single intervention can be said to be responsible for improving prisoners' mental health and/or reducing reoffending, early observations presented in this article demonstrate that the new CSIP Health Trainers in one establishment have the potential to contribute positively to both of these agendas through engaging fellow prisoners in work relating to areas such as healthy eating, exercise and stress management as outlined below.

\section{Improving prisoners' mental health}

Prisoners interviewed in this study had almost completed their training, and were already making positive changes to their own attitudes and behaviour. This reflects research on peer educator projects that suggests that they can result in a change in the behaviour of the peer educators themselves (Parkin \& McKeganey, 2000).

Additionally, they were also beginning to change the behaviour of their peers, for example, beginning to influence their diets. Research suggests that maintaining a balanced diet and the inclusion/exclusion of certain foods/nutrients can have a direct effect on mental health. A report by the Mental Health Foundation suggests that:

'As well as its impact on short and long-term mental health, food plays an important contributing role in the development, management and prevention of specific mental health problems such as depression, schizophrenia, attention deficit hyperactivity disorder, and Alzheimer's disease' (2006: 5).

Similarly, Mind's Food and Mood project examines the effect of diet on the way that people feel and states that making changes to what you eat can result in improvements in areas such as depression, insomnia and anxiety (Geary, 2004).

Thus, changes that Health Trainers make to their own and their peers' diets may have a positive impact on their mental health. However, there are limits to the extent to which prisoners can vary their diet in prison, and meals are usually provided at set times, so learning from this section of the course may be of more benefit to prisoners when they are released. The extent to which prison Health Trainers successfully improve their peers' diets should be investigated in further research.
As part of the course, prisoners were also learning about the benefits of exercise and the variety of exercises that can be done in prison. This may lead to an increase in the amount of exercise that Health Trainers and their peers undertake. Research shows that engaging in exercise can be an effective treatment for depression (Dunn et al, 2005; Dimeo et al, 2001). Therefore, over time this may lead to a reduction in the numbers of prisoners experiencing depression and may contribute towards a reduction in self-harm/suicide among prisoners.

There are also a number of possible positive implications of training prisoners to recognise and manage stress. Prisoners undergoing the training should be able to recognise the signs and symptoms of stress in themselves, and be able to manage them positively. Therefore, individuals participating in the course may actively change the way that they respond to stress, which could arguably lead to improvements in their mental health. It may change the way that individuals react to stressful situations, which may contribute to reducing the likelihood of these individuals re-offending.

Additionally, a reduction in prisoners' stress levels may lead to staff spending less time managing incidents on the wings, and to fewer demands being placed on prison health care centres to treat stress-related illnesses. As in peer-education schemes, this may mean that health care staff have more time to treat more 'complex' cases (Devilly et al, 2005).

Thus, prisoners may represent an untapped resource for reducing health inequalities and promoting access to services for a marginalized group. However, one must note that this is based on a focus group with prisoners at only one establishment and the role may be arguably less successful elsewhere. It may be inadvisable to generalise from the results of this small study beyond this establishment.

\section{Reducing re-offending}

Research demonstrates that offenders on probation are unlikely to be in employment (Mair \& May, 1997) due to issues such as low levels of qualifications and literacy problems. However, finding employment vastly reduces an individual's likelihood of re-offending (HM Government, 2005). Long-term, there are hopes that the CSIP Health Trainer project will play a part in addressing this problem as individuals trained to act as Health Trainers in prison will be released with an N/OCN 
qualification and will then be able to be employed as Health Trainers in the community.

Additionally, research indicates that personal factors such as health problems, low self-esteem and selfconfidence, and low levels of qualifications can also act as barriers to offenders finding employment (Rolfe, 2001). Health Trainers' work with prisoners may contribute towards removing some of these barriers through improving their health and increasing their self-esteem. Thus, training prisoners as Health Trainers can contribute to the government's plan to reduce re-offending through skills and employment (HM Government, 2005).

However, as highlighted by the Health Trainers themselves, there is a possibility of prisoners abusing this role. Research on other peer-education schemes suggests that in order for it to be successful, careful consideration needs to be given to how Health Trainers will be supervised. The types of advice that Health Trainers give and/or referrals that they make need to be carefully monitored with clear procedures for accountability (Devilly et al, 2005). Prison staff should ensure that prisoners receive adequate training for the role, receive regular supervision, and know the limits of their capabilities (Devilly et al, 2005). Discussions between Health Trainers and their clients should remain confidential. However, as Devilly et al (2005) state, prisoners also need to be aware of when confidentiality should be breached (eg. threat of harm to another), and there should be clear procedures for cases where confidentiality is breached inappropriately. Prison staff should also monitor the impact of Health Trainers on service provision, and ensure that enough Health Trainers are trained to allow equal access to the service for all prisoners. If these recommendations are followed, CSIP Health Trainers may successfully improve their own health and that of their peers, and may also have an increased chance of finding employment on release, which may reduce their chances of re-offending.

\section{Conclusion and recommendations}

This paper has summarised progress made on a pilot project aiming to adapt the community Health Trainer role for use in prisons. It has briefly outlined the training package produced by this project, paying particular attention to the parts that may have an influence on prisoners' mental health. Findings in this study suggest that training prisoners as Health Trainers has the potential to enable prisoners to make positive changes to their own attitudes and behaviour and to be able to influence their peers' behaviour too. Changes that Health Trainers make in areas such as diet, exercise and stress management may impact positively on prisoners' mental health. Offenders infrequently access mainstream health care services and may arguably see a CSIP Health Trainer's advice as more credible than that of a 'professional'. Thus, prisoners themselves represent an untapped resource for improving offender health. Moreover, it may be possible for prisoners to be employed as Health Trainers on release, which may reduce their chances of re-offending. However, this study was conducted at a relatively early stage in the pilot CSIP Health Trainers' project, investigating the views of prisoners at just one establishment.

The Health Trainer role will begin to be implemented across the prison estate on a larger scale later this year. At this point, in order to see whether the findings of this small-scale study are reflected elsewhere, further research should be conducted into the effect of both community and prison-based Health Trainers on individuals' mental health (both their clients and their friends/family). This could focus on areas such as:

- the cost effectiveness of Health Trainers compared to other professional groups

- the potential ethical issues of training prisoners as Health Trainers - in relation to any power imbalances/breaches of confidentiality that may occur between prisoners as a result

- the effectiveness of different models of supervising/managing the Health Trainer role

- investigating the types of health issues that clients discuss with Health Trainers - to add another dimension to existing (prison based) health needs assessments; how do the issues that prisoners discuss with CSIP Health Trainers compare with those that they discuss with health care staff? Is there any evidence that prisoners prefer to seek advice from a peer rather than a professional?

- the impact of referrals from Health Trainers on health service provision - do the number of referrals to particular services dramatically increase? If so, does this result in longer waiting lists, or in changes to the way in which services are provided in order to meet the increased demand? Do Health Trainers really increase the numbers of individuals from deprived 
areas accessing health services? Will the introduction of prison-based Health Trainers really reduce the number of stress-related referrals to health care staff, allowing them to devote additional time to more 'complex' cases?

- the extent to which Health Trainers are able to produce and maintain positive behaviour changes in their clients eg. change of diet, and the impact of these on their clients' mental health

- Health Trainers' career pathways - what types of employment do community-based Health Trainers move onto? What proportion of prison-based Health Trainers find employment in this area when they are released?

\section{Address for correspondence}

Coral Sirdifield

Research Assistant

CCAWI

Court 11

Faculty of Health, Life and Social Science

University of Lincoln

Brayford Pool

Lincoln LN6 7TS

Web: http://www.lincoln.ac.uk/cjmh/

\section{References}

Birmingham L, Mason D \& Grubin D (1996) Prevalence of mental disorder in remand prisoners: consecutive case study. British Medical Journal 313 1521-1524.

Brooker C, Repper J, Beverley C \& Ferriter M (2002) Mental Health Services and Prisoners: a review for the Department of Health [online]. Sheffield: ScHARR, Sheffield University. Available at: www.dh.gov.uk/assetRoot/04/06/43/78/04064378.PDF [Accessed 12 March 2007].

Brooker C, Ricketts T, Lemme F, Dent-Brown K \& Hibbert C (2005) An Evaluation of the Prison In-reach Collaborative, NHS National Programme on Forensic Mental Health Research and Development [online]. Sheffield: ScHARR, Sheffield University. Available at: http://www.nfmhp.org.uk/MRD\%2012\%2046\% 20Final\%20Report.pdf [Accessed 12 March 2007].

Brooker C (2006) An evaluation of the Roll-out of the 'Mental Health Awareness' Self-directed Workbook in Custodial settings, Final Report to the Department of Health [online]. Brayford Pool: University of Lincoln. Available at: http://www.lincoln.ac.uk/ cjmh/Evaluation_of_the_mha_workbook_Jan_9th_2007.pdf [Accessed 12 March 2007].

Brugha T, Singleton N, Meltzer H, Bebbington P, Farrell M, Jenkins R, Coid J, Fryers T, Melzer D \& Lewis G (2005) Psychosis in the community and in prisons: a report from the British National Survey of Psychiatric Morbidity. American Journal of Psychiatry 162 774-780.

Coffey A \& Atkinson P (1996) Making Sense of Qualitative Data. London: Sage Publications.

Department of Health (2004) Choosing Health: Making Healthy Choices Easier. London: Stationery Office.

Department of Health \& Her Majesty's Prison Service (2001) Changing the Outlook: a strategy for developing mental health services in prisons. London: DoH.

Devilly GJ, Sorbello L, Eccleston L \& Ward T (2005) Prison-based peer-education schemes. Aggression and Violent Behavior 10 (2) 219-240.

Dimeo F, Bauer M, Varahram I, Proest G \& Halter U (2001) Benefits from aerobic exercise in patients with major depression: a pilot study. British Journal of Sports Medicine 35 114-117.

Dunn AL, Trivedi MH, Kampert JB, Clark CG, \& Chambliss HO (2005) Exercise treatment for depression: efficacy and dose response. American Journal of Preventative Medicine 28 (1) 1-8.

Geary A (2004) The Mind Guide to Food and Mood. London: Mind.

Her Majesty's Government (2005) Reducing Re-Offending Through Skills and Employment. London: Stationery Office.

Her Majesty's Inspectorate of Prisons (1996) Patient or Prisoner: a new strategy for healthcare in prisons. London: DoH.

Her Majesty's Prison Service \& Department of Health (2001) Prison Health Policy Unit Task Force Annual Report 2000/2001. London: HMD/DoH.

Her Majesty's Prison Service (2006) HMPS population bulletins. [online]. London: HMPS. Available at: http://www.hmprisonservice.gov.uk/resourcecentre/publications documents/index.asp?cat=85 [Accessed 17 November 2006].

Home Office (2001) Prison Statistics England and Wales 2000. London: Home Office.

Kitzinger J (1995) Qualitative research: Introducing focus groups. British Medical Journal 311 299-302.

Mair G \& May C (1997) Offenders on Probation Home Office Research Study 167. London: Home Office.

Mental Health Foundation (2006) Feeding Minds: the impact of food on mental health. London: Mental Health Foundation.

Parkin S \& McKeganey N (2000) The rise and rise of peer education approaches. Drugs: education, prevention and policy 7 (3) 293-310

Rolfe H (2001) Barriers to Employment for Offenders and Exoffenders: Part Two - A Review of the Literature, Research Report No. 155. London: Department for Work and Pensions.

Singleton N, Meltzer H \& Gatward R (1998) Psychiatric Morbidity Among Prisoners in England and Wales. London: Office for National Statistics.

Social Exclusion Unit (2002) Reducing Re-offending by Ex-prisoners. London: SEU. 